\title{
AN ALGEBRAICALLY EXACT EXAMINATION OF JUNCTION FORMATION AND TRANSMISSION IN PARENT.OFFSPRING INBREEDING
}

\author{
Sir RONALD A. FISHER \\ Department of Genetics, University of Cambridge
}

\section{INTRODUCTION}

THE Theory of Junctions in inbreeding was first sketched in the third chapter of the author's Theory of Inbreeding (1949). This was by no means a thorough treatment, being confined to the case of sib-mating. It was intended to illustrate the method by which the extent to which the germ-plasm is subjected to recombination in the course of a complete inbreeding programme, and thence the frequency with which at each stage the entire line becomes homogenic, can be calculated. In the author's opinion the course of events cannot be halted, or even greatly retarded, by moderate differences in viability; but, in the case of such bisexual organisms as the house-mouse must often be completed in forty or fifty generations.

In $1953 \mathrm{~J}$. H. Bennett published in Genetica a paper on "Junctions in Inbreeding " giving comparative results for three other cases, namely $(a)$ self-fertilisation in disomics, (b) self-fertilisation in tetrasomics, and (c) alternate parent-offspring mating in bisexual forms. In the last case it was remarkable that complete homogeneity appeared to set in some three generations earlier than in the case of sib-matings, which in many other respects it closely resembles.

The author has been struck by some minor discrepancies in the last series of results and, since the case is in some respects of especial simplicity, has been led to explore so far as to see if exact expectations at all stages could not be calculated instead of the asymptotic formulae he had previously used. Some inaccuracies in the original discussion have in the meanwhile been corrected in "A fuller theory of junctions in inbreeding" in Heredity (Fisher, 1954).

As will be seen in the following account, Bennett's conclusion that homogeneity is attained, at each level of probability, rather earlier by parent-offspring than by sib-matings is confirmed, but the difference appears to be less than was thought, ranging in the relevant region from about $\mathrm{I} \cdot 8$ to about $\mathrm{I} \cdot 6$ generations.

The symbols $a, b, c, d$ are used to specify the tracts, in the neighbourhood of any particular point, introduced into the line by the foundation mating. The symbol $j$ is used for a junction always taken to be between tracts $a$ and $b$, so as to resemble $a$ on one side and $b$ on the other. With these conventions the various possible types of mating may be specified concisely. It seems probable that the small discrepancies mentioned above are due in part to inconsistencies in the numbering of the generations. 
Without junctions, parent-offspring inbreeding starts with an unrelated mating, generation zero, leading to the first mating of offspring with parent. This is typically trigenic, but will lead to segregating digenic types of three kinds in accordance with the standard matrix.

\begin{tabular}{|c|c|c|c|c|}
\hline Generation & 0 & & $a b$ & $=c d$ \\
\hline , & I & & $a c$ & $=a b$ \\
\hline & Mat & & & \\
\hline Offspring & $a b$ & $a b$ & $a b$ & $a a$ \\
\hline Parent & $a c$ & $a b$ & $a a$ & $a b$ \\
\hline Frequency & $x$ & $v$ & $u^{\prime}$ & $u$ \\
\hline$a b=a c$ & 2 & - & - & - \\
\hline$a b=a b$ & I & I & I & - \\
\hline$a b=a a$ & - & - & - & $\mathbf{I}$ \\
\hline$a a=a b$ & I & $\mathfrak{I}$ & I & - \\
\hline & $\tau$ & 2 & 2 & I \\
\hline
\end{tabular}

From this it appears, since in generation (I) the mating must be of trigenic type, that

$$
\begin{aligned}
x_{n} & =\left(\frac{1}{2}\right)^{n-1} \\
v_{n}=u_{n} & =-\frac{1}{2}\left(\frac{1}{2}\right)^{n-1}+\frac{1}{10}(\mathrm{I}+6 \epsilon) \epsilon^{n-1}+\text { conjugate } \\
u_{n}^{\prime} & =-\frac{1}{2}\left(\frac{1}{2}\right)^{n-1}+\frac{1}{10}(2+2 \epsilon) \epsilon^{n-1}+\quad,
\end{aligned}
$$

Hence for $s>0$, the fraction of the strands still heterogenic is

\begin{tabular}{|c|c|c|}
\hline $\begin{array}{l}s \\
0\end{array}$ & $\underset{\text { I }}{\text { Numerator }}$ & $\begin{array}{l}\text { Percentage } \\
\text { I00 }\end{array}$ \\
\hline $\begin{array}{l}1 \\
2 \\
3 \\
4 \\
5\end{array}$ & $\begin{array}{r}2 \\
4 \\
7 \\
12 \\
20\end{array}$ & $\begin{array}{l}100 \\
100 \\
87 \cdot 5 \\
75 \cdot 0 \\
62 \cdot 5\end{array}$ \\
\hline $\begin{array}{r}6 \\
7 \\
8 \\
9 \\
10\end{array}$ & $\begin{array}{r}33 \\
54 \\
88 \\
143 \\
232\end{array}$ & $\begin{array}{l}51 \cdot 5625 \\
42 \cdot 1875 \\
34 \cdot 375 \\
27 \cdot 92969 \\
22 \cdot 65625\end{array}$ \\
\hline $\begin{array}{l}\text { II } \\
12 \\
13 \\
14 \\
15\end{array}$ & $\begin{array}{r}376 \\
609 \\
986 \\
1596 \\
2583\end{array}$ & $\begin{array}{r}18 \cdot 3593^{8} \\
14 \cdot 86816 \\
12 \cdot 03613 \\
9 \cdot 72900 \\
7 \cdot 88269\end{array}$ \\
\hline
\end{tabular}

$$
-\left(\frac{1}{2}\right)^{s}+\frac{1}{10}(6+\mathrm{I} 6 \epsilon) \epsilon^{s}+\frac{1}{10}(14-\mathrm{I} 6 \epsilon)\left(\frac{1}{2}-\epsilon\right)^{s}
$$

TABLE I

Table I. Percentage of map length still heterogenic, illustrating the continuous method of calculation of the numerator

to be divided by $2^{s}$.

$$
\mathcal{N}_{s}=\mathcal{N}_{s-\mathrm{x}}+\mathcal{N}_{\mathrm{s-2}}+\mathrm{I}
$$




\section{INTERNAL JUNCTIONS OF TYPE $(a, b, j)$}

The trigenic and digenic types produce the internal junction type $(\delta)$, in particular,

$$
a j=a b
$$

with frequency

$$
u_{s}^{\prime}+2 v_{s}+\frac{1}{2} x_{s}
$$

or, appearing in generation $(s+\mathrm{I})$

$$
-2\left(\frac{1}{2}\right)^{s}+\frac{1}{10}(6+16 \epsilon) \epsilon^{s}+\text { conjugate, }
$$

and of these the fraction $\left(\frac{1}{2}\right)^{n-s-1}$ survive as internal junctions $(a, b, j)$ to generation $n$. But is

$$
{ }_{1} S^{n-1}\left(\frac{1}{2}\right)^{n-s-1}\left\{-2\left(\frac{1}{2}\right)^{s}+\frac{1}{10}(6+\mathrm{I} 6 \epsilon) \epsilon^{s}+\frac{1}{10}(14-16 \epsilon)\left(\frac{1}{2}-\epsilon\right)^{s}\right\}
$$

\begin{tabular}{|c|c|c|c|}
\hline Generation & $\mathrm{N}$ & $(\delta)$ & $(a)$ \\
\hline $\begin{array}{l}1 \\
2 \\
3 \\
4 \\
5\end{array}$ & $\begin{array}{r}0 \\
2 \\
8 \\
20 \\
42\end{array}$ & $\begin{array}{l}0 \\
\cdot 50000 \\
I \cdot 00000 \\
I \cdot 25000 \\
I \cdot 31250\end{array}$ & $\begin{array}{r}I \cdot 00000 \\
\cdot 50000 \\
\cdot 25000 \\
\cdot 12500 \\
\cdot 06250\end{array}$ \\
\hline $\begin{array}{r}6 \\
7 \\
8 \\
9 \\
\text { 10 }\end{array}$ & $\begin{array}{r}80 \\
144 \\
250 \\
424 \\
708\end{array}$ & $\begin{array}{r}I \cdot 25000 \\
I \cdot I 2500 \\
\cdot 97656 \\
.82812 \\
\cdot 69 r_{41}\end{array}$ & $\begin{array}{l}\cdot 03125 \\
\cdot 01562 \\
\cdot 00781 \\
\cdot 00391 \\
\cdot 00195\end{array}$ \\
\hline $\begin{array}{l}11 \\
12 \\
13 \\
14 \\
15\end{array}$ & $\begin{array}{l}1170 \\
1920 \\
3136 \\
5106 \\
8296\end{array}$ & $\begin{array}{l}\cdot 57129 \\
\cdot 46875 \\
\cdot 38281 \\
\cdot 31165 \\
\cdot 25317\end{array}$ & $\begin{array}{l}\cdot 00098 \\
.00049 \\
.00024 \\
.00012 \\
\cdot 00006\end{array}$ \\
\hline
\end{tabular}

$$
\frac{1}{10}(14+44 \epsilon) \epsilon^{n-1}+\frac{1}{10}(36-44 \epsilon)\left(\frac{1}{2}-\epsilon\right)^{n-\mathrm{I}}-(2 n+3)\left(\frac{1}{2}\right)^{n-\mathrm{I}} \text {. }
$$

Table 2 shows the calculation of these expected frequencies.

TABLE 2

Table 2. Expected numbers for Ioo $\mathrm{cM}$ of map length of internal junction $(a, b, j)$, with two original elements $a, b$, and a third derived from them by recombination. If either $a$ or $b$ is lost the junction is transmitted as an external junction.

Recurrence relation :-

$$
\mathcal{N}_{s}=\mathcal{N}_{s-1}+\mathcal{N}_{s-2}+(4 s-6)
$$

\section{OTHER TYPES OF INTERNAL JUNCTIONS}

The trigenic junctions $(a, b, j)$ derived from

$$
a j=a b
$$

are the only kinds derivable from digenic matings, yet the foundation mating,

$$
a b=c d,
$$


and trigenic types,

$$
a b=a c,
$$

derived from it, yield three other kinds of internal junction.

(a) The type

$$
c j=a b
$$

involving both original strands $a$ and $b$, the crossover strand $j$ derived from them, and a strand $c$ having nothing in common with the others, is completely transient, leading never to itself, but always to

or

$$
\begin{aligned}
& a c=c j \\
& a j=c j .
\end{aligned}
$$

Being transient, the frequency is simply that of production by crossing-over in the previous generation. But, in the foundation mating, crossing-over occurring in the mate to be used a second time, leads to this type, while crossing-over in the other mate is ineffectual, since both the original strands are simultaneously lost.

Moreover, from the trigenic matings

$$
a b=a c
$$

it arises with frequency $\frac{1}{2}$ for each unit of map length, and therefore from generation 2 onwards, it must appear with frequency

$$
2\left(\frac{1}{2}\right)^{n}
$$

as also in the first generation.

These also are shown in table 2.

$(\beta)$ The types $(a, c, j)$ constitute the total output of $(\alpha)$, and therefore appear new in generation $n(n>1)$ with frequency

$$
4\left(\frac{1}{2}\right)^{n} \text {. }
$$

They are also half the output by recombination from the trigenic types and this supplies as much again by a different path.

These are

$$
a j=a c \text { and } c j=a c .
$$

The new production (for $s>\mathrm{I}$ ) is then

$$
8\left(\frac{1}{2}\right)^{s}
$$

and the type is maintained in half the descendants in each generation; consequently by generation $n$ there has accrued

or

$$
\begin{aligned}
& S_{s=2}^{n} 8\left(\frac{1}{2}\right)^{s}\left(\frac{1}{2}\right)^{n-s} \\
& 8(n-\mathrm{I})\left(\frac{1}{2}\right)^{n} .
\end{aligned}
$$


$(\gamma)$ These types $\beta$, or $(a, c, j)$ are of six kinds, with the generation matrix shown below

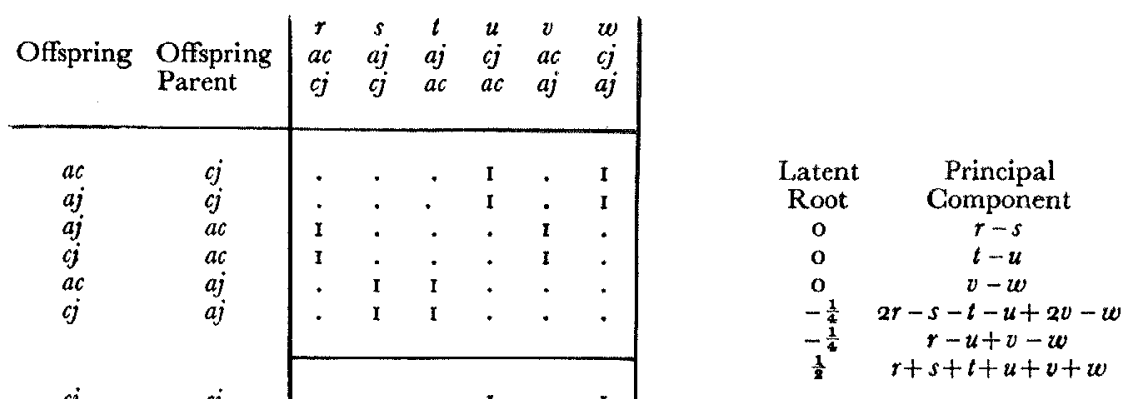

The first four are supplied anew at rate $2\left(\frac{1}{2}\right)^{8}$ each, when $s>1$; after $n-s$ generations

$$
u_{n}+w_{n}=\frac{1}{3}\left\{4\left(\frac{1}{2}\right)^{n-3}-\left(-\frac{1}{4}\right)^{n-s}\right\}\left(\frac{1}{2}\right)^{s-1},
$$

summed from $s=2$ to $n$, this is

$$
\frac{4}{3}\left(n-\frac{7}{6}\right)\left(\frac{1}{2}\right)^{n-1}+\frac{2}{9}\left(-\frac{1}{4}\right)^{n-1},
$$

so that a new production of type $(\gamma)$ appears in the $n^{\text {th }}$ generation with frequency

$$
\frac{4}{3}\left(n-\frac{13}{6}\right)\left(\frac{1}{2}\right)^{n-1}-\frac{4}{9}\left(-\frac{1}{4}\right)^{n-1}
$$

from $n=3$.

For the last enumeration then we may note that the probability of these remaining after $s-n$ further generations, as a junction $(c, j)$ of type $(\gamma)$, is

$$
\frac{1}{10}(3+8 \epsilon) \epsilon^{s-n}+\frac{1}{10}(7-8 \epsilon)\left(\frac{1}{2}-\epsilon\right)^{s-n} \text {. }
$$

The process of summation from $n=3$ to $n=s$ is somewhat intricate, but the result is similar to those of the other cases. Algebraically, it is

$$
-(4 n+2) 2^{-n}+\frac{1}{5}(6+16 \epsilon) \epsilon^{n}+\frac{1}{5}(14-16 \epsilon)\left(\frac{1}{2}-\epsilon\right)^{n},
$$

which can be evaluated continuously by the recurrence formula

$$
\mathcal{N}_{s}=\mathcal{N}_{s-1}+\mathcal{N}_{s-2}+(4 s-10)
$$

dividing at each stage by $2^{s}$.

Table 4 summarises the expected numbers per Ioo $\mathrm{cM}$ of strand, of the four types of internal junctions. 
TABLE $_{4}$

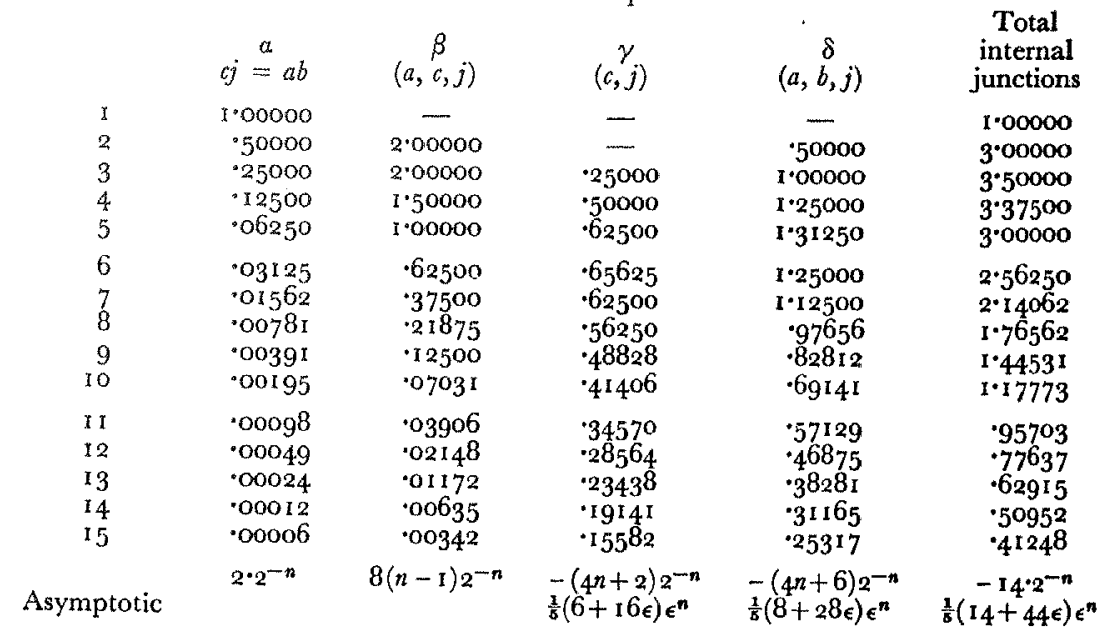

TABLE 5

\begin{tabular}{|c|c|c|c|}
\hline & $\begin{array}{c}\text { Total } \\
\text { internal }\end{array}$ & $\begin{array}{c}\text { Total } \\
\text { junctions }\end{array}$ & External \\
\hline $\begin{array}{l}1 \\
2\end{array}$ & $\begin{array}{l}r \cdot 00000 \\
3 \cdot 00000\end{array}$ & $\begin{array}{l}1 \cdot 00000 \\
3 \cdot 00000\end{array}$ & E \\
\hline 3 & 3.50000 & $4 \cdot 50000$ & 1.00000 \\
\hline 4 & $3 \cdot 37500$ & $5 \cdot 25000$ & $\mathrm{I} \cdot 87500$ \\
\hline 5 & 3.00000 & $5 \cdot 5625^{\circ}$ & $2 \cdot 56250$ \\
\hline 6 & $2 \cdot 56250$ & 5.56250 & 3.00000 \\
\hline $\begin{array}{l}7 \\
8\end{array}$ & $\begin{array}{l}2 \cdot 14062 \\
x \cdot 76562\end{array}$ & $5.3593^{8}$ & $3 \cdot 11875$ \\
\hline 9 & $\begin{array}{l}70502 \\
1.44531\end{array}$ & $\begin{array}{l}5.03125 \\
4.63281\end{array}$ & $\begin{array}{l}3 \cdot 26562 \\
3 \cdot 18750\end{array}$ \\
\hline ro & I.I7773 & $4 \cdot 20312$ & $\begin{array}{l}3.02539 \\
3.02\end{array}$ \\
\hline I I & $\cdot 95703$ & $3 * 76855$ & $2 \cdot 81152$ \\
\hline I 2 & .77637 & $3 \cdot 34668$ & $2 \cdot 5703 \mathrm{I}$ \\
\hline 13 & .62915 & $2 \cdot 94849$ & $2 \cdot 31934$ \\
\hline 14 & $\cdot 50952$ & $2 \cdot 58032$ & $2 \cdot 07080$ \\
\hline 3 & $.4124^{8}$ & $2 \cdot 24524$ & $1 \cdot 83276$ \\
\hline & $\begin{array}{c}-14^{-12}-n \\
+\frac{1}{\delta}(14+44 \epsilon) \epsilon^{n}\end{array}$ & $\frac{1}{5}(-2+8 \epsilon) \epsilon^{n}$ & $\begin{array}{c}14^{*} 2^{-n} \\
+\frac{1}{8}(6+16 \epsilon) .\end{array}$ \\
\hline & & $+\frac{n-1}{5}(6+\mathrm{r} 6 \epsilon) \epsilon^{n}$ & $(n-5+2 \epsilon) \epsilon^{n}$ \\
\hline
\end{tabular}

The total of junctions current in generation $n$ is

$$
\begin{aligned}
& \frac{1}{5}(-2+8 \epsilon) \epsilon^{n}+\frac{1}{5}(2-8 \epsilon)\left(\frac{1}{2}-\epsilon\right)^{n} \\
+ & \frac{n-1}{5}\left\{(6+16 \epsilon) \epsilon^{n}+(14-16 \epsilon)\left(\frac{1}{2}-\epsilon\right)^{n}\right\} .
\end{aligned}
$$

If from this is subtracted the total of internal junctions, the difference representing at each stage the expected number of external junctions, is given by the general formula

but

$$
\begin{gathered}
\mathrm{r} 4 \cdot 2^{-n} \\
+\frac{1}{5}(n-\mathrm{I})(6+\mathrm{r} 6 \epsilon) \epsilon^{n}+\text { conjugate } \\
+\frac{1}{5}(\mathrm{I} 6+36 \epsilon) \epsilon^{n}+\quad " \quad \\
\mathrm{I} 6+36 \epsilon=(6+\mathrm{I} 6 \epsilon)(4-2 \epsilon)
\end{gathered}
$$


so the expected number of external junctions may be written

$$
\begin{gathered}
14 \cdot 2^{-n} \\
\frac{1}{5}(n-5+2 \epsilon)(6+16 \epsilon) \epsilon^{n}+\text { conjugate term. }
\end{gathered}
$$

\begin{tabular}{|c|c|c|}
\hline & $m$ & $\begin{array}{c}\text { Probability } \\
e^{-m}\end{array}$ \\
\hline $\begin{array}{l}25 \\
26 \\
27 \\
28 \\
29\end{array}$ & $\begin{array}{l}5 \cdot 30832 \\
4^{\circ} 4^{8609} \\
3 \cdot 7843^{\circ} \\
3^{*} \cdot 8695 \\
2 \cdot 67973\end{array}$ & $\begin{array}{l}\cdot 00495 \\
\cdot 01126 \\
\cdot 02272 \\
\cdot 04130 \\
\cdot 06858\end{array}$ \\
\hline $\begin{array}{l}30 \\
31 \\
32 \\
33 \\
34\end{array}$ & $\begin{array}{l}2 \cdot 25001 \\
1.88669 \\
1 \cdot 58007 \\
1.32176 \\
1.1044^{8}\end{array}$ & $\begin{array}{l}\cdot 10540 \\
\cdot 15157 \\
\cdot 20596 \\
\cdot 26667 \\
\cdot 33139\end{array}$ \\
\hline $\begin{array}{l}35 \\
36 \\
37 \\
38 \\
39\end{array}$ & $\begin{array}{l}\cdot 92198 \\
\cdot 768 \mathrm{gr} \\
\cdot 64068 \\
\cdot 5333^{8} \\
\cdot 443^{69}\end{array}$ & $\begin{array}{r}-39773 \\
+46352 \\
+52693 \\
+58662 \\
+64167\end{array}$ \\
\hline $\begin{array}{l}40 \\
41 \\
42 \\
43 \\
44\end{array}$ & $\begin{array}{l}3688 \mathrm{I} \\
\cdot 30635 \\
\cdot 254^{29} \\
\cdot 2 \mathrm{I} 095 \\
\cdot 17488\end{array}$ & $\begin{array}{r}69155 \\
\cdot 73613 \\
\cdot 77547 \\
\cdot 80982 \\
\cdot 83955\end{array}$ \\
\hline $\begin{array}{l}45 \\
46 \\
47 \\
48 \\
49\end{array}$ & $\begin{array}{l}\cdot \text { I } 4490 \\
\cdot \text { I } 1999 \\
\cdot 09931 \\
\cdot 08215 \\
\cdot 06792\end{array}$ & $\begin{array}{r}-8651 \text { I } \\
\cdot 886993 \\
\cdot 90546 \\
\cdot 92114 \\
\cdot 93434\end{array}$ \\
\hline $\begin{array}{l}50 \\
51 \\
52 \\
53 \\
54\end{array}$ & $\begin{array}{l}\cdot 05614 \\
\cdot 04637 \\
\cdot 03829 \\
\cdot 03160 \\
\cdot 02608\end{array}$ & $\begin{array}{l}\cdot 94541 \\
\cdot 95468 \\
\cdot 96244 \\
\cdot 96889 \\
\cdot 97375\end{array}$ \\
\hline $\begin{array}{l}55 \\
56 \\
57 \\
58 \\
59\end{array}$ & $\begin{array}{l}\cdot 02151 \\
\cdot 01773 \\
01461 \\
0101204 \\
\cdot 00992\end{array}$ & $\begin{array}{l}97872 \\
\cdot 98242 \\
\cdot 98549 \\
\cdot 98803 \\
\cdot 99013\end{array}$ \\
\hline 60 & .008 I 6 & $\cdot 99187$ \\
\hline
\end{tabular}

TABLE 6

Note.-The distribution of the probability of elimination of the last heterogenic tract by generations would be very similar to that shown in Fig. I of Fisher (1954) for sib-mating, but about I generations earlier.

\section{THE NUMBERS OF HETEROGENIC TRACTS}

For a number of generations exceeding 20, only the leading terms need be considered. If $L$ is the total length of strand, the number of external junctions expected will be

$$
\frac{1}{5}(n-5+2 \epsilon)(6+\mathrm{I} 6 \epsilon) \epsilon^{n} L
$$

and if $\nu$ is the number of chromosomes, the number of chromosome ends still heterogenic will be

$$
\frac{1}{5}(6+I 6 \epsilon) \epsilon^{n} \nu .
$$


The expected number of heterogenic tracts will be half the sum of these, or

$$
m=\frac{1}{5}(3+8 \epsilon) \epsilon^{n}\{(n-5+2 \epsilon) L+\nu\} .
$$

Putting, as is approximately appropriate for mice,

$$
L=25, \nu=20 \text {, }
$$

it appears that at 25 generations $m$ has fallen to about 5.3 , and the probability that the whole material is homogenic, $e^{-m}$, is just under I per cent. The value up to $n=60$ of $m$ and of the derived probability, are shown in table 6.

The values shown in table 6 correspond closely to the corresponding probabilities for sib-matings published in 1954. The first quartile, 25 per cent., is passed between the 32 nd and the $33^{\text {rd }}$ generations, whereas with sib-mating it falls between the $34^{\text {th }}$ and the $35^{\text {th. }}$. Fifty per cent. is passed between generations 36 and 37 instead of between 38 and 39 , while the third quartile, 75 per cent., is between generations $4 \mathrm{I}$ and 42 , instead of 43 and 44 . These comparisons suggest a difference of two generations, while a more accurate interpolation of the probabilities gives a difference of about $\mathrm{r} \cdot 8$ at 25 generations falling very slightly to about $\mathrm{I} \cdot 6$ at 60 generations, when in both cases complete homozygosis is almost certainly attained.

\section{SUMMARY}

For the comparatively simple system of inbreeding by alternate parent-offspring matings exact algebraic expressions can be found for the proportion of the germinal strands expected at each stage to be heterogenic, and for the expected number of junctions, external and internal, at each stage. The internal junctions are of four kinds, three of which are derived in a kind of cascade, requiring fairly careful analysis. It seemed therefore useful to explore the possibility of such an exact examination.

\section{REFERENCES}

BENNETT, J. H. 1953. Junctions in inbreeding. Genetica XXVI, 392-406. PISHER, R. A. I 949 . The Theory of Inbreeding. Oliver and Boyd Ltd., Edinburgh. FISHER, R. A. 1954. A fuller theory of "junctions" in inbreeding. Heredity, 8, I87-I97. 